\title{
Escritura, vocación y compromiso ideológico en Carlos D roguett: La "conciencia crítica" de los narradores chilenos*
}

Writing, vocation and ideological compromise in Carlos D roguett: The "critical consciousness" of chilean narrators

\author{
Santiago Aránguiz Pinto \\ Universidad Diego Portales, Chile \\ E-mail: santiago.aranguiz@udp.cl
}

\section{I. "ESCRIBIR ES LLEGAR A SER HOMBRE"}

NAD A de medias tintas ni concesiones de ningún tipo. $C$ arlos $D$ roguett fue un escritor al que le gustaba decir las cosas de frente y sin remordimientos. Comprometiendo la amistad que muchos de sus coetáneos le profesaban, aunque no la manifestaron públicamente por temor a posibles reproches, arriesgando incluso la estabilidad laboral que en algunas oportunidades le significó conseguir trabajos poco gratificantes y ajenos a su actividad literaria, D roguett no se amilanó ante nadie para denunciar lo que, según él, debía ser un imperativo moral: la honestidad de los escritores eintelectuales chilenos. Además, quería revelar el nulo compromiso ideológico con que los escritores asumen el trabajo literario, lo que implica una preocupante apatía queluego se transforma en desgano e incluso en una sumisión que desl egitima cualquier acción de protesta para denunciar públicamente determinadas acciones políticas tendientes a establecer la hegemonía económica y militar de un pás.

El escritor, sostiene D roguett, necesariamente debe instalarse en la sociedad como la "conciencia crítica" de su tiempo, asumir un compromiso ético irrevo-

\footnotetext{
* Esta investigación se encuentra enmarcada dentro deun proyecto "Semilla" dela U niversidad D iego Portales. Agradezco el apoyo y los comentarios de mi mujer, M aría José Amigo, y de Alfredo Jocelyn-H olt y $M$ arcelo $D$ roguett $L$ azo, con quienes adeudo un sincero aprecio, gratitud y respaldo. Asimismo, mi reconocimiento a Constanza Ramírez, quien trabajó como ayudante de investigación en el libro que será editado prontamente por el sello UDP.
} 
cable, muy en la línea de la irrestricta obligación ideológica que tuvo un núme ro nada despreciable de intelectuales alineados con la Revolución Cubana, implicando un adoctrinamiento que, finalmente, provocó nefastas consecuencias para la libertad de expresión en América Latina. El "caso Padilla" es el más conocido de ellos. G eneró una revuelta de proporciones entre intelectuales y escritores que se agolpaban en los dos bandos opuestos del espectro ideológico de entonces durante la década de 1960 en medio de la guerra fría: el socialismo o la democracia liberal. Para D roguett no había alternativa posi ble: o se apoyaba el proyecto del socialismo revolucionario o se estaba con el "enemigo" imperialista, los Estados U nidos de N orteamérica.

N o hay forma más clara que explicarlo de este modo: "Escribir es llegar a ser hombre", sentenció en una oportunidad. Para D roguett, no existía otra manifestación más explícita de las ansias de comprender del ser humano y de la realidad quela escritura. Allí, en la redacción de una novela o de un relato residía la verdadera vida de la literatura, y no, como muchos otros escritores suponían, y así se lo reprochaban al propio $D$ roguett, estudiar analíticamente la propuesta literaria de un narrador o poeta. Eso era para los especialistas y profesores de literatura, no para un escritor quecreaba, y que no sólo se dedicaba a "reproducir" o a enseñar lo que otros escribían. Por ende, el hombre era aquel que se proponía comprender la compleja realidad humana a través de la escritura, en el entendido de que sólo ella era capaz de crear un tipo de literatura que diera cuenta de la complejidad que había originado el ejercicio artístico original.

Asimismo, le causaba una enormeindignación a $D$ roguett el hecho de queel escritor tuviera una actitud condescendiente hacia las transformaciones políticas, sociales y culturales que se vivieron durante el siglo XX, marcado a fuego por feroces confrontaciones bélicas en Europa y la aparición de ideologías totalitarias como el fascismo, el nacional social ismo o el stalinismo. D esde esta posición, el escritor, afirmaba D roguett, no podía estar ausente de aquello que era consustancial a su trabajo: exponer sin temor alguno la crudeza de la realidad social frente a la cual tenía que lidiar diariamente, pese a que ésta fuese angustiosa y destemplada para muchos. Al mismo tiempo, el escritor, aducía D roguett, a través de su trabajo literario, tanto en el periodismo como en novelas y relatos, debía denunciar los abusos cometidos por quienes detentan el poder político y económico en América Latina, continente frenteal cual mostró un permanente interés por conocer la situación histórico-social de sus países.

Tampoco dudó un instante para referirse en términos drásticos a aquellos narradores que sólo se preocupaban por desarrollarse profesionalmente en vistas a obtener éxito comercial por sus libros, pero que no ejercían una labor "revolucionaria", a la manera como D roguett la entendía, es decir, concebir la literatura y el ejercicio literario al servicio de la causa doctrinaria que imponía el credo 
socialista impulsado por Guevara y C astro. D e nada contribuye el escritor a la causa revolucionaria cuando elabora sesudas creaciones literarias si es que dicho trabajo creativo no está acompañado de una convicción profunda de que aquél debía ejercer una función social de primer orden en una sociedad que pretendía establecer normas de conducta afines a un ideario socialista tendiente a la equidad social y a una adecuada distribución del ingreso. El escritor debe entregarse por entero a su trabajo literario, involucrando en el proceso creativo sus más acentuados convencimientosideológicos y, además, la capacidad que posea para escudriñar en los abismos más remotos del alma humana:

Para mí, la literatura es un acto total que interesa al cuerpo y al espíritu del escritor: en términos teológicos, como un sacramento; en términos psiquiátriCos, como un suicidio. Si el escritor no se satura de pasión por su tema y por su personaje, se queda en la superficie, transitoriamente y para siempre en la superficie. Yo soy un pasional y mi pasión es la literatura, pasión de vida y no de muerte (...) El escritor que no escribe por la justicia es un despojador de los pobres, un ladrón ${ }^{1}$.

La escritura, para D roguett, en tanto ejercicio concreto de expresar determinados pensamientos y a la vez manifestación de sensibilidades y emociones, involucra tanto al cuerpo como al espíritu del narrador, entregarse por entero, depositar en ella la respiración, el corazón y las entrañas de su ser. Y esta misma pasión que traspasó su literatura fue la que le valió muchas veces la exclusión del medio literario chileno que no estaba acostumbrado a arrebatos de franqueza de un escritor que no transó sus convicciones por nada del mundo. En más de una oportunidad la sinceridad le jugó una mala pasada, aunque nunca se arrepintió de lo que dijo o hizo, por más que ello implicara exponerse a las más severas recriminaciones verbales o vejaciones físicas, como ocurrió en algunas oportunidades. No se dejó vencer fácilmente ante las adversidades, las que no lo dejarían de perseguir por una buena cantidad de años. Prefirió, en cambio, acrecentar aún más su ya abultada galería de enemigos, que crecía a un ritmo vertiginoso, pero de los cuales no se atemorizaba en lo más mínimo, sabiendo de sus capacidades argumentativas.

Algunas de las principales características de la narrativa de $D$ roguett fueron sin duda la pasión y el compromiso, la honestidad y la entrega a toda prueba, además de un dominio cabal del lenguaje, una extraordinaria capacidad para delinear personajes traspasados por dosis considerables de humanidad y ternura

\footnotetext{
${ }^{1}$ Entrevista realizada por el periodista Tomás P. M ac H ale, "Carlos D roguett: 'Soy un pasional y mi pasión es la literatura', publicada en El M ercurio, Santiago, 24 de enero de 1971, p. 2.
} 
al mismo tiempo. Y poseer, además, un conocimiento acabado de técnicas literarias y de autores franceses, rusos y anglosajones, principalmente Proust, D ostoievski, Chéjov, Poe, Tolstoi, Joyce, K afka, H amsun, Faulkner, M ann, Celine y M ichaux. Fueron ellos quienes le enseñaron que el escritor no debe asumir una posición de claudicación frente a la realidad, pues debe tratar de comprenderla, aun sabiendo de que ello puede acarrearle al artista perjuicios y lamentos pero que no descansa en conseguir la consecución de sus objetivos, significándole, posteriormente, una recompensa espiritual que sobrepasará la envidia o el rencor de quienes han tratado de aportillar su trabajo creativo: "Porque todo arte queno refleja el tiempo presente está condenado a morir mañana, no atravesará el tiempo, como deseaba Proust para todo arte verdadero"2. El tipo de arte al cual hace alusión D roguett debía sustentarse en la autenticidad de su trabajo, quea la vez deberá ser una extensión de una vida dedicada de lleno a la creación, asumiendo a toda hora y en todo momento una conciencia crítica quele permita dedicarse por entero a un compromiso social asumido desde el momento mismo en que decide convertirse en escritor.

Así de tajante fue en sus apreciaciones. N ada de cortejos ni venias. Como decíamos anteriormente, aunque ahora lo expresemos de otra manera: para D roguett el trabajo literario del escritor implicaba necesariamente sacrificar todo, absolutamente todo, por la "causa" a la cual estaba destinado cumplir. N o tenía escapatoria, ni menos alternativa posible. No obstante sus abultados conocimientos sobre teoría literaria, producto de su gran capacidad de lectura en su condición de autodidacta, desestimó dar definiciones complejas y elaboradas para definir el oficio literario, y el suyo, por supuesto, pero desde un primer momento asume una entrega irrestricta, que no merece duda al guna. Privilegia, en cambio, la espontaneidad, la lección maestra que nos enseña la vida de su propia experiencia: “M i ideal sería llegar a escribir como respiro, con la extrema sencillez que lo hace esa estupenda improvisadora que es la vida".

\section{TRAS LOS PASO S DEL LIBERTAD OR}

Compromiso y pasión manifiesta D roguett ante todo para exponer a través de la literatura una realidad que muchas veces aparecía transfigurada por la radicalidad histórica de los acontecimientos; una realidad a la que no supo sino atenerse en su más estricto fervor ideológico, el mismo por el cual respaldó hasta

\footnotetext{
2 Entrevista concedida al periodista, crítico literario y escritor Antonio Avaria para la revista Arbol de Letras $\mathrm{N}$ 0 3, febrero de 1968, pp. 20-21, publicada por la Editorial Universitaria.

3 Op. cit., p. 21.
} 
las últimas consecuencias a la Revolución Cubana, la que consideraba como el acontecimiento cultural de connotaciones liberadoras más significativo que había parido el siglo XX y frente a la cual tendrá las más elogiosas palabras de admiración y respeto, especialmente por Fidel Castro, a quien consideraba el "tábano socrático para ambas Américas. Es real mente uno de los hombres más extraordinarios de este siglo"4, y por el Che Guevara, de quien incluso tenía una foto en el escritorio de su hogar ubicado en el popular barrio Franklin, como demostración del afecto que sentía por él. La devoción que profesó por José M artí sobrepasó cualquier tipo de admiración al considerarlo un "santo popular" que traspasó cualquier tipo de representación social humana para instalarse entre los emancipadores que liberaron a América durante el siglo XIX, tanto más importante que J osé de San M artín o Bernardo 0 'H iggins ${ }^{5}$.

D ebido a su actitud disconformey al desengaño que le profesaba a los partidos políticos, en alguna fracción de la izquierda latinoamericana $D$ roguett concitó desconfianza y resquemor al punto de que se le consideró un disidente político, un intelectual outsider que se dispuso no transar ni por todo el oro del mundo los principios éticos con los cuales regía su existencia, y que supo hacer de la resistencia una forma de encarar la complejidad delas relaciones humanas, traspasadas por la violencia, el horror, la muerte y la marginalidad. Jamás se dejó arrastrar por manifestación alguna de fanatismo o por la fal ta de visión crítica que éste le reprochaba a un sector determinado de la izquierda chilena al asumir una actitud condescendiente. D roguett representa el polo opuesto a Jorge Edwardsy $M$ ario Vargas Llosa, quienes no vacilaron en manifestar públicamente su rechazo por Fidel Castro y sus políticas culturales. D roguett, en cambio, prefiere alinearse con la posición ortodoxa de Julio Cortázar y Gabriel García $M$ árquez, quienes se mantuvieron impertérritos ante las denuncias que exponían en 1971 los abusos cometidos por el régimen castrista en contra del poeta isleño H eberto Padilla, quien tuvo que padecer la reclusión carcelaria por manifestar una opinión disidente a la dictadura establecida en aquel país.

Es sabido que tanto Edwards como el peruano fueron considerados "traidores" por la izquierda latinoamericana dogmática, la cual estimó inaceptable e "inmoral" el reproche formulado por ambos intelectuales. Al negarse a adscribir dogmáticamente a un credo ideológico, cualquiera éste sea, o incluso inscribirse

${ }^{4}$ Ibíd.

${ }^{5}$ Carlos D roguett, "La pregunta que no puedo contestar: iqué ha significado para ti la Revolución Cubana?, publicado en Casa de las Américas, La H abana, Año XIX, № 112, enero-febrero de 1979, pp. 11-21.

"D roguett se refiere extensamente al "caso Padilla" en el ensayo "El escritor y su pasión necesaria", publicado en Casa de las Américas, La H abana, Año XII, № 68, septiembre-octubre de 1971, pp. 60-68. 
en el Partido Socialista pese a sus simpatías por esta fracción política, D roguett también fue víctima de los ataques de quienes militaban en partidos políticos, de funcionarios de las reparticiones públicas o miembros de las cúpulas culturales oficialistas, lo que le significó en buenas cuentas carecer del apoyo necesario para ascender laboralmente en la administración pública, como era el afán de muchos escritores eintelectuales. Y así seguir escalando hasta conseguir puestos detrabajo que implicasen mayor grado de poder, poder queD roguett despreció al considerarlo nocivo para ejercer de manera independientela labor intelectual en plenitud de las facultades.

La profunda devoción que profesó D roguett por los principios social istas se hizo evidente con el incondicional apoyo que le brindó a Salvador Allende y al gobierno de la Unidad Popular en los momentos más apremiantes de su administración, sin por ello dejar de hacer manifiesta su discrepancia sobre algunas decisiones que le parecían erróneas, o que, en su defecto, no satisfacían los requerimientos dela sociedad chilena que lo había el egido para implementar transformaciones profundas en la sociedad chilena. D espués del suicidio de Allende y del golpe de Estado de septiembre de 1973, D roguett asumió una postura de ferviente compromiso con el gobierno depuesto por las armas, desacreditando la intromisión de las Fuerzas Armadas en la conducción política del país. N unca, a decir verdad, mostró simpatías por el Ejército ni tampoco hacia las instituciones de orden, criticando el preponderante desempeño que éstas habían ejercido en la sociedad chilena y también en el resto de América Latina. Esta situación, aduce, ha provocado queC hilese haya transformado en un país militarista y de espíritu bélico, subsumido en un ambientehostil y de confrontación con los países vecinos, y, lo que es más dañino todavía, con los propios ciudadanos chilenos.

Comprometido, leal, consecuente y entregado por entero a causas que consideraba justas defender, incluso si es queello significaba al gún tipo de perjuicio inmediato, D roguett no dejó de profesarle admiración a Allende, quien, según él, encarnó los val ores éticos más al tos de la historia de C hile, al ofrecer su vida como inmolación y sacrificio de toda una nación 7 . M ás que Balmaceda incluso, quien también se inmoló por susideales, y se ha transformado en el "mártir" de la democracia para muchos, pero para otros, en cambio, representa la figura del gobernante ineficaz y autoritario, quien llevó a una sangrienta guerra civil, la más cruenta de la historia de Chile.

\footnotetext{
${ }^{7}$ C onsúltese para estos efectos los siguientes textos: "Compañero Presidente", en D efile, 11 de diciembre de 1970, pp. 30-31 (incluido en la primera parte de estelibro) y "D iálogos sobre Salvador Allende", en Literatura chilena. Crítica y exilio, California, EE.UU ., Vol. 7, N 3, julio-septiembre de 1983, pp. 10-16.
} 
Los artícul os que $D$ roguett publicó en las revistas M ensaje y $D$ effile durante los primeros años de la década de $1970^{8}$ reflejan la propensión para analizar la realidad de Chile desde una visión integral y aguda a la vez, con un especial énfasis en los aspectos social es y culturales, los mismos a los cual es se les destinó una persistente preocupación durante la U nidad Popular. Este material periodístico, enviado desde Europa por expresa petición del periodista y narrador Antonio Avaria, constituyela manifestación más representativa del bullente proceso creativo en el cual se encontraba inmerso D roguett, entusiasmado por la ocasión única que tenía C hile de transformarse en un país ideológicamente de avanzada, con un especial acento en el desarrollo de la literatura, el arte y la cultura, un país en el cual se erradicaría la pobreza y la desigualdad social, y también fomentaría el desarrollo de las artes y la creación literaria. Sólo bajo estas condiciones, aduce D roguett, Chile será capaz de constituirse en un país que podrá disfrutar de la libertad individual y de los beneficios económicos administrados por el Estado.

\section{COMPROMISOS A TODA PRUEBA}

Al igual que su amigo Pablo de Rokha, de quien tuvo elogiosas palabras de gratitud y admiración, D roguett también cultivó una relación disconforme, de acucioso escepticismo con la sociedad y el entorno social que lo rodeaba, al punto de que se le consideró un escritor huraño, distante del resto de sus compañeros, solitario, e incluso desdeñoso con el trabajo literario del resto de los narradores chilenos. A ambos los unió una amistad entrañable que se expresó en una generosidad a toda prueba, reafirmada por sentimientos de amistad y cariño mutuo. D roguett poseía todas las obras del autor de Los gemidos, las que desaparecieron, junto a los originales de Eloy y Patas de perro, cuando su hogar fue saqueado por la DIN A después de que C arlos e I sabel salieron de Chile en septiembre de 1975, una vez que obtuviera la liberación de su hijo M arcel que se encontraba recluido en I sla Teja. Con algunas excepciones, siendo quizás la más gravitante el respeto que le profesó a $\mathrm{D}$ e Rokha, D roguett emitía palabras condenatorias para la gran mayoría de los narradores nacionales, considerando a muchos de ellos creadores pusilánimes, carentes de una voz propia e independiente de presi ones doctrinarias o de intereses económicos, ajenos a las motivaciones ideológicas y sociales que afligen a la sociedad, cultivadores de un arte

\footnotetext{
${ }^{8} \mathrm{G}$ ran parte de ellos fueron recopilados en el libro Escrito en el aire. Valparaíso: Ediciones U niversitarias de Val paraíso, 1972.
} 
ficticio o superficial, queno guarda relación alguna con las vicisitudes del mundo contemporáneo.

La lista es larga y variada, eincluye desde algunos criollistas hasta el autor de Canto general. Así, Eduardo Barrios, M ariano Latorre, Alone, Pablo N eruda y muchos otros se convirtieron en el blanco de ataque de $D$ roguett, quien no soportaba la intriga y la falta de ética de los escritores, los cuales, según él, partido político mediante 0 academias, trabajaban afanosamente para conseguir becas o concursos estatales. Aunque cueste creerlo, D roguett también desplegó palabras elogiosas para algunos escritores como Vicente Pérez Rosales y Baldomero Lillo y, entresus contemporáneos, N icomedes G uzmán, Juan G odoy, Francisco Coloane, M anuel Rojas y Alberto Romero. Pese a la cercanía ideológica que mantuvo con algunos de sus miembroso simpatizantes, D roguett nunca tuvo relaciones deamistad con el Partido Comunista chileno ni tampoco con la Sociedad de Escritores de C hile, a la cual nunca quiso pertenecer, pues consideraba que nada más lejano a su visión de lo que debía ser (y proceder) el escritor, el hecho de matricularse en una institución que prefería reglamentar la libertad creativa del narrador en vez de impulsar la vocación narrativa. El no se prestaba para jugarretas pseudo-intelectuales que únicamente fomentaban la desidia y la autocomplacencia, colindantes las más de las veces con credos políticos de raigambre autoritaria.

Por cierto, pleitos nunca le faltaron, ya sea imaginarios o reales, inventados por él mismo o propiciados temerosamente por contrincantes que ansiaban "pelear" con un rival de temer, como una manera de confirmarse a sí mismo de sus capacidades argumentativas, y asimismo como una manera de tener en la raya a quien osara cruzarse sobre su camino. Pero también hubo de los verdaderos, aquellos que sufrieron la mordacidad que lo caracterizó. Los altercados más Ilamativos, al menos de los que se tenga constancia por los medios de comunicación, los sostuvo con N icanor Parra y Luis Sánchez Latorre. En ambos casos D roguett no dilapidó tinta para enarbolar su enfurecida pluma. Algunos tuvieron mejor suerte y salieron ilesos del cuadrilátero por la batalla de egos y reconocimientos, los mismos por los cuales $\mathrm{H}$ uidobro, De Rokha y $\mathrm{N}$ eruda se trenzarían en la guerrilla literaria de mayores proporciones de la historia de la literatura chilena.

En vez de realizar un trabajo de estímulo hacia los creadores nacionales, al entando la publicación de novelas y otorgando becas para la creación literaria, este organismo prefería concretarse, denunciaba D roguett, en el comidillo literario enfrascado en disputas ideológicas partidistas, tendientes únicamente a beneficiar a quienes formaban parte de aquellos grupúsculos. Tampoco tuvo intenciones de matricularse en ninguna otra institución política o cultural, cuya única función es la de adoctrinar creencias ideológicas y afinidades estéticas que, 
para D roguett, no deben ceñirse a reglamentos que coarten la libertad de las personas. El hecho de pertenecer a un determinado partido político, de acuerdo a este escritor, es dar por aceptado la preeminencia de estatutos de los cuales muchas veces uno discrepa, pero que termina aceptándolos por inercia, y de esta manera posibilita la legitimación de un discurso oficialista anacrónico e incluso ficticio. D roguett no se prestaba para ese tipo de jugarretas. Tampoco consideraba necesario atender estas situaciones que él estimaba de bajeza moral, por cuanto significaban irremediablemente una distracción del trabajo de concientización social y cultural que debía realizar tanto el escritor como el intelectual en resguardo de su bien más preciado: la autonomía crítica para emitir opiniones y desarrollar una activa función revolucionaria en el campo de la creación artística.

No importaba desde qué lugar real izaba la invectiva, ya sea por intermedio del ensayo, de la crónica o de la columna de opinión, para $D$ roguett lo fundamental consistía en que el escritor debía necesariamente asumir una labor de imprecación social y una función ética ejemplar, de la misma manera como Jesús ejerció como defensor de los afligidos e indefensos. Este fue el primer revolucionario en el mundo según D roguett; el único y genuino revolucionario que ha pisado la tierra. En efecto, a pesar de su acendrada fe en el terreno de la ideología revolucionaria, se consideraba a sí mismo un hombre profundamente religioso, al punto de afirmar que "Cristo me impresiona. M e llega hasta dar rabia su vida, su muerte, siento envidia"9. En muchas de sus obras, especialmente en El compadre (1967) y D espués del diluvio (1971), anida una angustia cristiana y un profundo sentimiento religioso que se explica, de acuerdo a D roguett, en el hecho de que haya sido educado en un colegio católico y que su libro de cabecera haya sido la Biblia.

Representa, sin duda, un caso atípico, poco convencional dentro de la fauna literaria chilena, acostumbrada más bien a prefigurar narradores sumisos, carentes de la fogosidad vociferante que poseyó D roguett. U na curiosa mezcla de escritor místico-religioso e intelectual revolucionario con aficiones mundanas e inquietudes doctrinarias deavanzada, preocupado del aspecto social desde un punto de vista práctico y concreto, nada de elucubraciones metafísicas ni engaños populistas. Franco, directo y sincero, no era de aquellos que se refocilaba en discusiones bizantinas; prefería callar si es que no tenía nada interesante que aportar, pero cuando lo hacía, era precisamente para arremeter con todo y denunciar los abusos que se cometían en desmedro de los más desvalidos de la sociedad.

El único trabajo de genuina importancia que debe emprender el creador

\footnotetext{
${ }_{9}^{9}$ Palabras recogidas en la entrevista concedida a Antonio Avaria para la revistaArbol de L etras $\mathrm{N}$ 3, febrero de 1968, pp. 20-21.
} 
literario, señala, es el de encarar la realidad tal cual se presenta, a ratos cruda y desencantada, y denunciar los atropellos e injusticias cometidos hacia los más débiles y aquellos que sufren la postergación social. Y, lo que es más reprochable aún, el hecho de que aquello ocurre reiteradamente entre quienes se autoproclaman "defensores del pueblo" pero que, en realidad, quieren beneficiarse de su posición laboral y social para obtener ventajas que les permitan acceder a una posición aventajada en ministerios, universidades, municipalidades 0 en centros culturales. D e manera que la realidad se constituye en un eje articulador fundamental para concebir el único posible para D roguett de las relaciones entre los seres humanos. A la vez, permite establecer un provechoso diálogo entre memoria ehistoria (tanto individual como colectiva), que corresponde a uno de los asuntos más interesantes de examinar en este autor, en tanto nos remite a una "negación del olvido" ${ }^{10}$ como una manera de resistir la amnesia característica de los chilenos, y de no ceder ante quienes prefieren borrar la historia de un plumazo y extraviarse en la desinformación, en el desgano, en la falta de interés por conocer el acontecer histórico nacional con todas sus complejidades.

Pese a lo anterior, no se puede desconocer que D roguett fue un escritor con acendrados pensamientos ideológi cos de izquierda y de ardorosas afecciones por la problemática social y comunitaria, aunque debemos precisar a quénos referimos con esto, pues él mismo se encargó de enfatizar que, pese a su ligazón con miembros y conducta propias del socialismo anti-autoritario y de un pensamiento anarquista de cuño cristiano, era un intelectual que no se sujetaba a ningún mandato partidista ni tampoco a dictámenes emitidos por camarillas. Prefirió enarbolar, en cambio, su propios estatutos programáticos, los cuales, por lo demás, estaban muy lejos de ceñirse a normativas doctrinarias, y que gozó de una salud inquebrantable al mantenerse alejado de cualquier tipo de rencilla política destinada a buscar mayores cuotas de poder y figuración.

Lejos de ser un náufrago despotricando en su isla, aislado y sumergido en los fangos de la ira y el desprecio, que él se propuso representar vehementemente, aun a sabiendas de los costos personales que ello le podía acarrear. Algunos escritores como M anuel Rojas y G onzález Vera compartieron con él una amistad fraterna que se prolongó por décadas y un lineamiento ético común, apega-

\footnotetext{
${ }^{10}$ Este asunto está trabajado por Soledad Bianchi en el ensayo "La negación del olvido: hacia una poética de Carlos Droguett", en Coloqui o Internacional sobrela obra deCarlos D roguett, pp. 2531. Esta es la publicación académica más importante escrita por varios autores que ha dado cuenta críticamente de su compleja obra narrativa de manera consistente y abarcando una significativa variedad de temáticas y aspectos de su proceso creativo. Participan en dicha instancia, realizada en mayo de 1981, Ios siguientes investigadores: Teobal do N oriega, M ayrse Renaud, Jacqueline Covo, Cecilia Zokner, Luis Iñigo M adrigal, N icasio Perera San M artín, Jaime Concha, Antonio M elis, Fernando M oreno y Alain Sicard.
} 
do a un sentimiento de humanismo fraterno derivado de una experiencia de reiterados sacrificios durante sus vidas, marcadas durante la juventud por un acendrado escepticismo hacia el Estado y las instituciones en la medida en que éstas absorben al ser humano y lo convierten en un miembro incógnito de una masa amorfa e irreconocible, en una multitud que, por el hecho de pertenecer a un organismo público, ha perdido el rostro de su identidad, su verdadera esencia a fin de cuentas.

Siguiendo esta línea argumentativa, existe un nexo común que emparienta a estos tres autores - y también a Pablo de Rokha y Alberto Romero-, tanto en la actitud de encarar la vida como también en la propuesta estética de sus narraciones, traspasadas por la creación de personajes lacerados, ambientes tensos y desgarradores, silencios mitigantes envueltos por una tensa opacidad luminosa, y, además, por el designio inescrutable de la condición humana. M arcados por las vicisitudes de una existencia áspera y ruda, vulnerada por pérdidas humanas dolorosas, que luego vertían en sus relatos de manera punzante, estos escritores comprendieron que la existencia humana está marcada por injusticias y sinsabores, pero también por la ternura y un profundo apego hacia las situaciones cotidianas del devenir, traspasadas por la facilidad con que D roguett se emocionaba reconociendo en la sencillez de un humilde trabajador el reflejo de su propia vida, expuesta como una existencia sacrificada al servicio de la literatura y el periodismo cultural, sin contar, por supuesto, el amor incondicional que profesaba por su esposa e hijos, quienes fueron sus amigos verdaderos y fieles compañeros. Cualquier oficio podía ser honorable, siempre y cuando fuese realizado con dignidad. "M i paso por la administración pública me ha enseñado - por lo menos- que puede haber más dignidad en un portero que en un ministro"11, señaló en una entrevista concedida al escritor Guillermo Blanco para la revista Ercilla.

\section{IV. "AME CON VERD ADERO ODIO"}

Provisto de una valentía sin igual en el medio cultural chileno, D roguett despotricó contra todo aquel quesecruzara por enfrente de su camino asumiendo una actitud de fanfarronería intel ectual, aun cuando aquello le significara el rechazo de escritores, redactores y editores, quienes serían las víctimas de su iracundia verbal, la que desperdigó con asombrosa generosidad por intermedio de la elevada cantidad de medios periodísticos en los cuales colaboró, o bien

${ }^{11}$ Guillermo Blanco, "Patas de perro, dientes de león", Ercilla, Santiago de Chile, 24 de noviembre de 1965, p. 41. 
cuando medrosos periodistas acudían a entrevistarlo para obtener la opinión de un escritor informado, culto, tajante en sus apreciaciones, que siempre estaba dispuesto a enfundar su espada para estocar a más de al gún intelectual desprevenido, derramando sangre ajena, con las consiguientes implicancias que ello significaba. Políticos y autoridades públicas no estuvieron ajenos a su ferocidad, ya sea para criticar la inescrupulosidad de los parlamentarios o bien para exponer la escasa preparación profesional deministros o funcionarios del Estado, a quienes generalmente les reprochaba la falta de probidad para ejercer cargos públicos responsablemente.

Por tales motivos, D roguett se ganó la mala fama -en algunos casos beneficiosa- de ser un escritor malhumorado, irascible, enérgico, que podía pecar de soberbia, pero, eso sí, jamás por su falta de honestidad o por cometer actos repudiables que comprometiesen su irrestricta ética. D elo anterior nadie dudó, pero sí le reprocharon en cambio haber sido miembro durante su juventud de las filas nacional social istas lideradas por Jorge G onzález Von M arées, 0 al menos haber tenido simpatías por este credo ideológico. El propio Droguett lo negó tajantemente, aduciendo una maquinación en su contra de algunos escritores que quisieron desprestigiarlo. Esta "mancha negra" todavía no ha sido esclarecida del todo, aunque nadie se ha entusiasmado para indagar este aspecto desconocido de su vida, que puede deparar más de alguna sorpresa.

Concluyente en sus apreciaciones e inflexible para definir la actitud de una persona, emitía comentarios condenatorios y definitivos. Sensible en momentos de angustia, se emocionaba con facilidad cuando tocaban susmás profundas fibras existenciales. Cariñoso en su hogar en la compañía de su familia, a quienes le profesaba un respeto sin igual. A tento y afable cuando se trataba de consolar a un amigo, D roguett desperdigó verdaderos gestos de confraternidad a quien más lo necesitaba. Lúcido, apasionado, irónico y cáustico, son sólo algunos de los apelativos que definen su personalidad, aunque también se caracterizó por su amor incondicional, persistentes signos de amistad y, por sobre todo, lealtad a toda prueba. De pocas palabras, pero contundentes, que sacaban chispas la mayoría de las veces. Tuvo escasas amistades, pero a quienes podía recurrir a toda hora y en todo momento, pues siempre estarían apoyándolo en momentos de aflicción. El círculo íntimo de amigos estaba compuesto por el padre Escudero, Pablo de Rokha, G onzález Vera, M anuel Rojas y Alberto Romero, a quienes consideraba amigos del alma y compañeros del sufrimiento y el dolor espiritual.

Conforme lo anterior, D roguett no tuvo beneplácitos de ninguna variedad con el siempre mezquino ambiente cultural en el cual estuvo inserto, más bien adverso y proclive a la mediocridad intelectual, escasamentecomprometido con la acción solidaria o la justicia, considerados por él como valores esenciales que 
todos los seres humanos deben poseer. Por sobre todo los escritores, en quienes recaía una responsabilidad social mayor, ya que son ellos los llamados a denunciar los abusos cometidos por la clase política y dirigente en beneficio de los sectores más postergados de la sociedad.

M uy comentados fueron en su momento sus bosquejos literarios sobre personalidades públicas que divulgó periódicamente en el diario Extra (creado por él y Juan de Luigi en 1946, luego de su destitución como reportero y articulista en Las U Itimas $\mathrm{N}$ oticias), siendo implacable en sus apreciaciones, trayéndole muchas veces la indiferencia y hasta el rechazo de amigos y compañeros de labores, quienes créan que se le "pasaba la mano" constantemente, no importándole los costos que le acarrearía el enojo de un parlamentario, o el hecho de que un escritor viera amancillado su orgullo, si es que le quedaba. La incomprensión queD roguett generó entre los intelectual es y narradores, deliberadamente odiosa y muchas veces injustificada, la utilizó para aportillar, a su manera, la mediocridad del literato chileno, prejuiciado y envidioso por antonomasia, de acuerdo a lo expresado en numerosas oportunidades por él mismo. D espotricó a diestra y siniestra contra todo aquello que consideraba indigno desde un punto de vista moral y reprochable éticamente, aun sabiendo que al adoptar una actitud intransigente podía extraviar a quienes él consideraba sus amigos más cercanos.

Prefería, en cambio, obedecer a sus valores éticos que granjearse la amistad de quienes, según éste, carecían de la consecuencia ética que la literatura imponía a aquellos que se consideraban a sí mismos escritores auténticos, dotados de una vocación literaria genuina. $\mathrm{N}$ o bastaba el hecho de haber publicado trabajos literarios muchas veces intrascendentes, si los comparamos con la significativa obra editada por D roguett, más aún si consideramos que los textos que todavía permanecen inéditos, según estimaciones de su hijo $\mathrm{M}$ arcelo, superan las 35.000 carillas. Son los coletazos del inconformismo que sembró la rebeldía de quien supo incomodar a moros y cristianos, mirando de frente y asumiendo en todo momento la responsabilidad de sus afirmaciones.

La repulsa que D roguett poseyó de algunos pensadores y escritores generó un desprecio que, a su vez, se convirtió en acicate para su perseverancia vocacional y, al mismo tiempo, en un repelente eficaz para espantar a todos aquellos que se sintieron incómodos ante la desfachatez de un intelectual que no tuvo pelos en la lengua para decir lo que tenía que decir, costara lo que costara. Cualquiera fuese el precio, no estaba dispuesto a amordazar su silencio para obtener el beneplácito de quienes no provocaban en él los más mínimos asomos de compostura. $\mathrm{Ni}$ las aflicciones económicas por las cuales tuvo que atravesar, cuando no contó con un trabajo remunerado de manera estable, lo distrajeron de su perseverancia creativa que aguantó penurias, manteniendo a su familia en una precaria situación material. Incluso, resistió ataques destemplados de quie 
nes tuvo la peor apreciación sobre ellos, considerados por él escritores mediocres, intelectual es de tercera categoría o bien políticos corruptos einescrupulosos.

En ese sentido, no hizo concesión de ningún tipo con el medio literario chileno, al cual consideraba dañino, egoísta, mezquino, con algunas justificaciones por supuesto, las mismas a las cuales él mismo se encargaba de promocionar en un país que posterga a los creadores, se olvida de ellos, lo que hace aún más dramática la situación laboral del escritor. Estos viven en una situación de absoluto desamparo y es en este clima adverso donde deben desarrollar su labor incendiaria a través de la literatura. Por esencia, el escritor debe definirse como un artista provocador y subversivo, adscrito más bien a la protesta y la denuncia que a lo acomodaticio, a la relajación propia de una sociedad burguesa preocupada exclusivamente del lucro que de la condición social y asistencial de las personas que la habitan. D roguett, qué duda cabe, era un rebelde que prefería sostener acal oradas discusiones con oponentes advenedizos que claudicar ante la embestida reluciente pero ineficaz de un tipo con ínfulas de pensador.

Salvo contadas excepciones, no dejaba títere con cabeza cuando se refería de manera enérgica a aquellos escritores que sólo se preocupaban de su beneficio personal y no optaban, en cambio, por llevar adelante una labor para denunciar las arbitrariedades cometidas por el desbocado abuso de poder de las autoridades públicas. Esto le valió ser considerado un escritor insoportable y odioso, y del cual nadie quiso sufrir la embestida letal de sus afirmaciones. "En un país de pusilánimes y de genuflexos no es raro que yo tenga fama de escritor agresivo"12, señaló en una ocasión cuando lo entrevistó el escritor Alfonso Alcalde, dequien tuvo una apreciación muy favorable ${ }^{13}$. La misma agresividad y coraje que desperdigó a montones, las que, unidas a un lenguaje desgarrador y sufriente, fueron sus mejores armas para atacar a sus enemigos - que proliferaban por doquier a medida que se volvía más incisiva la actitud de D roguett- y defender uno de los bienes más preciados que se vanaglorió poseer: la irreprochable conducta y la consecuencia política a toda prueba que le val ió afirmaciones lapidarias de al gunos escritores que, asu vez, fueron el blanco predilecto de las diatribas de D roguett.

Si bien existió una imagen pública de D roguett que se refería a su persona de forma lapidaria, alimentada por él mismo, sin duda, como una manera de establecer una muralla de protección en torno suyo, su grupo de amigos más cerca-

${ }^{12}$ En Alfonso Alcalde. 1971. Gente de carney hueso. Santiago de C hile: Ediciones Valores Literarios, p. 96.

${ }^{13}$ V éase al respecto el ensayo "La literatura chilena de espaldas ala realidad nacional", publicado en M ensaje, Santiago de Chile, № 202-203, septiembre-octubre de 1971, pp. 477-484. 
nos y familiares destacan deél su profunda humanidad, los actos de generosidad que desplegó, la ternura que sentía por su mujer, I sabel Lazo Acevedo, y el cariño que sentía por sus hijos $C$ arlos y $M$ arcelo, quienes reconocen que tuvieron un padre bondadoso y afectuoso, aunquesevero y exigente. La personalidad compleja y atribulada se refleja en sus obras de creación literaria de mayor aliento, donde confluyen aspectos tratados brevemente en algunas crónicas o artículos de opinión. En ellas examinó los más variados aspectos de la realidad social y política chilena einternacional, como así también escribió sobre un asunto del cual tuvo mucha competencia: Ia literatura y el proceso creativo que acompaña a los escritores. No tuvo complacencia alguna en sus juicios sobre la literatura chilena, al considerar que a ésta le faltaba valentía y coraje, y que, además, era incapaz de asumir compromisos para hacerse cargo de los abusos, crímenes e injusticias cometidos en la historia de C hile, desde el proceso de conquista del siglo XV, época caracterizada por la desolación y el arrojo, hasta el asesinato de Ios nacionalistas en 1938, pasando por la matanza de Pampa I rigoin en 1969, llegando final mentehasta la violencia política de Estado instaurada desde 1973 con la irrupción de los militares y las Fuerzas Armadas en el escenario político nacional.

Con su vehemencia habitual, D roguett acusará la falta de preocupación de los narradores locales en el afán de indagar determinados acontecimientos de la historia del país para, en cambio, refugiarse en temáticas insustanciales, que poco y nadaaportan a la conformación de una literatura "revolucionaria", como él mismo la denominó, comprometida con los combates que se libraban tanto en el terreno de la ideología, en la lucha política anti-partidista, como también en la propuesta discursiva librada por la narrativa y la estética literaria en general. Famosa y muy divulgada fue su eterna rivalidad que mantuvo con el poeta $\mathrm{N}$ icanor Parra, la cual se exacerbó con la rencilla que mantuvieron con ocasión de la visita de Parra a la Casa Blanca en una reunión con Pat $\mathrm{N}$ ixon, la señora del J efede Estado de los Estados U nidos, en abril de1970. D roguett no desperdició ni un minuto y lanzó su más dura artillería para denunciar lo que consideraba un acto conspirativo que denotaba claramente una actitud sediciosa en contra de las naciones alienadas al socialismo soviético, en momentos en quela G uerra Fría llegaba a uno de sus puntos más ál gidos de confrontación ideológica. Como respuesta, Parra llamó a D roguett "hijo de puta", generando consigo un revuelo insospechado en Chile, que desembocaría en una relación de odio profundo entre ellos, al punto de que los "parrianos" establecerán la existencia de dos bandos irreconciliables, afectando de esta manera la ya alicaída difusión de la obra de D roguett, en desmedro de la cada vez mayor adhesión hacia el antipoeta, provocando hoy día una seguidilla incondicional de adeptos y fanáticos. 


\section{V. "EL REVOLUCION ARISM O DEL ESCRITOR ESTA AQUI: RESCRIBIR LA HIST ORIA"}

En efecto, D roguett entendió el trabajo literario como un acto espiritual que requiere de un férreo compromiso ético y social, y que representa además una reafirmación de sus convicciones ideológicas y estéticas a través de una escritura tendientea remarcar permanentementela condición "humana" delosindividuos, la capacidad que éstos tienen de amar y odiar al mismo tiempo, de recordar y olvidar, de sufrir y emocionarse, de reconocerse a sí mismos como seres humanos limitados, pero que aspiran a mejores condiciones de bienestar y justicia social. Cuando se explaya sobrela literatura chilena y universal, no sólo se refiereal proceso creativo de un autor o un determinado libro, o reseñar a sus personajes, argumento y estructura narrativa. En cambio, opta por hacer del trabajo periodístico una labor de creación literaria en la cual exponer su interés particular por ciertos pasajes desconocidos de la historia de Chile y por determinados personajes tan variados como J esucristo, Pedro de Val divia, Inés deSuárez, Pero Sancho de la H oz, Juan N úñez de Prado, Emile D ubois, Ramón N eira (el protagonista de El compadre), Bobi (el niño de las extremidades caninas) y hasta el mismo padre Alfonso Escudero, profesor suyo en el Colegio San Agustín.

Recogiendo la idea esbozada anteriormente, podría afirmarse que $D$ roguett sigue siendo actualmente un autor desconocido en Chile, no así tanto en el resto de América Latina e incluso en Europa. No cabe ninguna duda, si consideramos la escasa atención prestada por los estudiosos e investigadores que no se han preocupado por analizar a uno de los escritores chilenos más prestigiosos, a un narrador que utilizó el periodismo con el mismo objetivo que un guerrillero emplea su fusil: para disparar a mansal va contra todo lo que representa una amenaza a su integridad, aunque también podría interpretarse como ceguera ideológica, y algo de eso hay, sin lugar a duda, en el pensamiento político de D roguett, quien nunca públicamente se refirió a los abusos cometidos durante el stalinismo 0 a la censura declarada por Castro en la Revolución Cubana.

Pese a haber obtenido importantes reconocimientos en Europa y en 1970 hacerse acreedor del Premio N acional de Literatura, ha sido un escritor desconocido y postergado sistemáticamente por académicos, críticos, ensayistas y público en general, quienes, en el mejor de los casos, no han podido acceder a su literatura por la falta de interés de las editoriales chilenas que majaderamente rechazaron la publicación de al gunos de sus títulos. C on excepción de dos, publicados el 2001: La señorita Lara y M atar a los viejos. Esta última novela fue constantemente rechazada por las editoriales nacionales, al punto de que, a causa de desestimaciones del editor de entonces, la Editorial Universitaria desistió

de su interés por publicar las obras completas de D roguett, quien se negó de 
manera persistente a eliminar la dedicatoria de ese libro, en la cual acusaba de asesinos a los miembros de la Junta $\mathrm{M}$ ilitar que fraguaron el golpe de Estado en septiembre de 1973. Ni la mayor oferta económica le impidió dar pie atrás frente a una decisión que no admitía revocación: la novela se publicabaíntegramente 0 no se editaba. No había otra posibilidad. La inquebrantable determinación fue también una característica que tuvo en numerosos otros aspectos de su vida cotidiana y del compromiso ideológico e intelectual asumido. Era un escritor de una sola palabra, y también de una sola mujer.

Paralelamentea su compromiso intelectual, quele significó la consideración de muchos escritores y pensadores latinoamericanos, profesó una profunda vocación literaria que no menguó ni un solo momento durante su vida, que iba aparejada del "revolucionarismo" al cual adscribió como dogma de fe, a la manera como un hombre religioso ofrende su existencia a la voluntad de Dios, de que Dios y la fe ideológica, para el caso de Droguett, van de la mano. No se puedeentender la responsabilidad intelectual que le cabe al escritor en la consecución de la instalación de valores cristianos e ideológicos afines a un ideario de izquierda de corte democrático y pacifista, si es que no se aborda la otra cara de la moneda: el deber queD roguett asumió en su vocación de escritor comprometido con la realidad delas sociedades, su fervor ideológico y, además, velar para quelos sectores marginales y más pobres no sigan sufriendo de la postergación a la cual son sometidos. D roguett no quiere-ni puede- olvidarsede ellos, en tanto constituyen la memoria de quienes persistentemente han sido excluidos de los beneficios materiales y de la asistencia social proporcionada por el Estado. Así lo refleja gran parte de su obra narrativa, tanto las novelas como sus textos periodísticos, que puede interpretarse como un ejercicio de permanente recuerdo, que es a la vez una manera de adquirir conciencia de la identidad que posee como ser humano dotado de libertad y autonomía capaz de criticar en función de sus valores y creencias.

$\mathrm{Ni}$ el propio D roguett tuvo una justificación explícita del impulso creativo que lo inundó para llevar adelante su labor literaria. Aunque reconoce la existencia de una fuerza vital artística, no sabe cómo evidenciar racionalmente dicho impulso: "N o podría explicar por qué escribo. ¿Por qué bebe el alcohólico? El diría que porque no lo puede evitar. Yo tampoco, y como él, no lo considero una desgracia. Es más bien una fatalidad, tomando la expresión en su significado esencial"14. Asimismo, tampoco posee nociones teóricas sobre su estilo literario, realzado por su escritura original y abigarrada, como lo han señalado críticos y ensayistas que han examinado su obra. Consciente de sus limitaciones

${ }^{14}$ En Antonio Avaria, Arbol de Letras N , febrero de 1968, p. 20. 
pero, a la vez, capacitado para ofrecer una explicación de su proceso creativo, no trepida ni un instante para asumir un irrestricto apoyo de su estilo literario, desordenado y atribulado, vigoroso y perturbador al mismo tiempo, como se le criticó, pero que, según él, respondía a la necesidad de penetrar con angustia y pasión en los vericuetos de la realidad, frente a la cual recurrió incesantemente para extraer de allí los materiales necesarios para tratar de explicar la complejidad de las relaciones humanas.

\section{CONSIDERACIONES FIN ALES}

La preocupación fundamental de este artículo ha sido examinar algunos de los rasgos más decisivos a través de los cuales $D$ roguett expresó su "conciencia crítica" en su obra narrativa, esto es, manifestar una posición clara y determinante sobre los problemas sociales, políticos, económicos e ideológicos que afectaban tanto a C hile, América Latina y a Europea en general. Así ocurrió, por ejemplo, con sus apreciaciones sobre la literatura chilena, la que, según él, debía asumir un compromiso con la sociedad chilena en su totalidad, la cual ha vivido "de espaldas" (término empleado por el propio D roguett) a la realidad nacional, ignorando lo acontecido en sus diferentes áreas, como si la creación literaria, aduce, estuviera al margen de los asuntos cotidianosy reales de las personas y los países. El trabajo creativo del escritor y la literatura, por extensión, constituyen pilares fundamentales de un proyecto ideológico mayor, capaz de poner al ser humano y sus necesidades al centro de las preocupaciones del Estado y la sociedad.

Esto implicó, por supuesto, que D roguett se viera expuesto a su vez a las descalificaciones de quienes se sentían ofendidos por sus aseveraciones, o bien rechazaran abiertamente sus ideas por considerarlas de "mal gusto", inapropiadas, antojadizas, carentes de fundamento y coherencia. El escritor y el intelectual, según $D$ roguett, necesariamentedeben asumir un compromiso ideológico acorde a la función "revolucionaria" asociada a la labor intelectual y creativa, la cual contempla además una remarcada voluntad de ponerse al servicio, ya sea en el trabajo creativo como en la labor manual, de una causa doctrinaria apoyada en valores humanistas, cristianos y, por sobre todo, afines a un ideario provocador y subversivo. Todo escritor que se definiera como tal, inexcusablemente debía apoyar y propagar a la vez los postulados rebeldes y agitadores irradiados por el marxismo-leninismo y, especialmente, por el idealismo socialista-popular propiciado por la Revolución Cubana encarnado en el Che Guevara, a quien consideraba como uno de sus máximosídolos, sintiendo una profunda admiración por su entrega inquebrantable en beneficio delos desposeídos y los marginados. 
No cabe ninguna duda de que esús era el eje principal de su pensamiento y de su forma de vida, por quien sintió un profundo afecto, llegando a sostener, incluso, que sentía envidia por él. Admiraba su humildad, la entrega, el valor y el sacrificio de su vida al servicio de los más necesitados, los desamparados, los "sin voz", la genteanónima, carente derostro eidentificación. N o hay nada más genuinamente "revolucionario", según D roguett, que el contenido político de la pal abra propagada por Jesucristo, en beneficio de quienes necesitaban de al imento y consuelo espiritual, de aquellos que anhelan cambiar el rumbo de sus vidas. D roguett se propuso seguir su ejemplo, renunciando a bienes materialesy sacrificán dose por entero a una causa que él creía justa y necesaria, para identificarse con los que sufren, con quienes quieren abrazar la doctrina pacifista y transgresora de Jesucristo. 
